\title{
A case of Bartter syndrome
}

\author{
R P S Rajapakshe ${ }^{1}$, G M Bandaranayake ${ }^{2}$, A P Wijesuriya ${ }^{3}$
}

Sri Lanka Journal of Child Health, 2010; 39: 148-149

(Key words: Bartter syndrome, hypokalaemia, metabolic alkalosis, polyuria, indomethacin)

\section{Introduction}

Bartter syndrome is a rare, recessive, defect of sodium and chloride absorption from the loop of Henle resulting in excessive urinary electrolyte losses. Due to volume depletion, hyperaldosteronism leads to hypokalaemia and metabolic alkalosis.

\section{Case Report}

A six month old boy of non-consanguineous parents was transferred to Lady Ridgeway Hospital, with cough and fever for 4 days, repeated vomiting and severe dehydration. Within the past three months he had suffered three similar episodes warranting hospitalization and IV fluids, but was normal between episodes and prior to onset. Antenatal period was not complicated by polyhydramnios, delivery was normal, birth weight was $3.5 \mathrm{~kg}$, and no perinatal insults were noted. Early infantile period was uneventful with normal development and weaning was started at $4 \frac{1}{2}$ months.

On admission, he was in hypovolaemic shock with tachycardia. After vigorous fluid resuscitation he was haemodynamically stabilized. His weight was $5.4 \mathrm{~kg}$, (1SD below $3^{\text {rd }}$ centile), length, $65 \mathrm{~cm}$, (between $10^{\text {th }}$ and $50^{\text {th }}$ centiles) and OFC $42 \mathrm{~cm}$ (between $3^{\text {rd }}$ and $10^{\text {th }}$ centiles). The infant had protruding ears and prominent eyes but no hyper pigmentation of skin or mucous membranes. Abdomen, genitalia and nervous system appeared normal. Following recovery, he was normotensive with good pulse volume. Growth chart demonstrated growth faltering from 3 months onwards.

His full blood count, blood urea, magnesium and creatinine were normal but despite serum sodium

${ }^{1}$ Registrar in Paediatrics, ${ }^{2}$ Senior Registrar in
Paediatrics, ${ }^{3}$ Consultant Paediatrician, Lady
Ridgeway Hospital for Children, Colombo

(Received on 10 August 2009. Accepted on 18 September 2009) being normal $(135 \mathrm{meq} / \mathrm{l})$, potassium $(2.5 \mathrm{meq} / \mathrm{l})$ and chloride $(92 \mathrm{meq} / \mathrm{l})$ were low. His arterial blood gas revealed metabolic alkalosis with a $\mathrm{pH}$ of 7.56 and serum and urinary osmolalities were $270 \mathrm{mosm} / \mathrm{kg}$ water and $159 \mathrm{mosm} / \mathrm{kg}$ water respectively. His urine electrolytes revealed increased excretion of sodium, potassium and chloride. Although normocalcaemic, his urinary calcium/creatinine excretion ratio was elevated (0.68), indicating hypercalciuria. His subsequent ultrasound scan of abdomen was normal. Serum renin was markedly elevated $(11.99 \mathrm{ng} / \mathrm{ml} / \mathrm{hr})$ [normal range 0.15-2.33].

Based on the clinical picture and laboratory data, after initial fluid and potassium correction, he was started on oral potassium chloride $2.5 \mathrm{mmol}$ twice/ day and indomethacin $2.5 \mathrm{mg}$ twice/ day. Response to treatment was evaluated for one week. His polyuria reduced drastically and the potassium level normalized. He was discharged later on same medications and parents were extensively advised on balanced weaning food with adequate potassium and sufficient fluids.

Clinic follow up revealed satisfactory weight gain without any further acute episodes with normal potassium levels and arterial blood gasses.

\section{Discussion}

Bartter syndrome was originally described by Federic Bartter in 1962 as a combination of hyperplasia of juxtaglomerular complex, hyperaldosteronism and hypokalaemic metabolic alkalosis ${ }^{1}$. It was traditionally classified as: neonatal, classical and Gitelman syndrome. But, with the advancement of genetic analysis, it is thought to be caused by mutations of genes encoding proteins that transport ions across renal cells in the thick ascending limb of loop of Henle ${ }^{1}$.

The current classification ${ }^{2}$ includes type I and II (neonatal or antenatal Bartter syndrome) due to defective NKCC2 and ROMK genes respectively, affecting the $\mathrm{Na}-\mathrm{K}-2 \mathrm{Cl}$ symporter predominantly. 
Type III, or 'classic' Bartter syndrome, is due to CLCNKB genetic defect causing abnormal basal chloride channel. Type IV is rare and the most severe combined loop and distal tubule dysfunction with associated sensorineural deafness due to CLCNKA or their beta subunit BSND genetic mutation ${ }^{3}$.

Of the sodium chloride filtered, $70 \%$ is reabsorbed in the proximal tubule while the remaining $30 \%$ is reabsorbed from the water impermeable thick ascending limb via a $\mathrm{Na}-\mathrm{K}-\mathrm{Cl}$ cotransporter driven by low intracellular concentration of sodium. When these are defective the cumulative result is a large volume of urine and increased amounts of sodium and potassium to distal parts of the renal tubule, leading to hypokalaemia, hypochloraemia and increased urinary excretion of these ions.

In neonatal Bartter syndrome, maternal polyhydramnios secondary to fetal polyuria occurs, and the newborn is at high risk of life threatening dehydration ${ }^{1}$. The child may demonstrate soft dysmorphism with triangular facies, large eyes, protruding ears and strabismus. The classic Bartter syndrome usually presents later with linear growth retardation, episodic dehydration, periodic paralysis, polydipsia, polyuria and recurrent carpo-pedal spasms. Although of no diagnostic importance, they may also show similar facies.

Establishment of hypokalaemia and hypochloraemia with metabolic alkalosis is vital for diagnosis ${ }^{1,2}$. Some patients demonstrate subtle hypomagnesaemia leading to a diagnostic dilemma with Gitelman syndrome in which magnesium levels are significantly low. To differentiate these two, although hypercalciuria is prominent in Bartter syndrome it is negligible in Gitelman syndrome in which magnesium excretion is greatly elevated ${ }^{2}$. In Bartter syndrome serum renin, aldosterone and prostaglandin E2 are elevated. Although renal biopsy is not essential for diagnostic purposes, the cardinal feature will be hyperplasia of juxtaglomerular apparatus in most specimens. A definitive diagnosis can be reached by genetic mutation analysis.

The treatment consists of proper hydration, potassium supplementation and indomethacin therapy ${ }^{4}$ which will blunt the prostaglandin overproduction and correction of hypokalaemia. Potassium sparing diuretic spironolactone may benefit transiently ${ }^{4}$. Nephrocalcinosis, chronic renal failure and short stature, a few known complications, should be addressed properly.

\section{References}

1. Rodriguez-Soriano J. "Bartter and related syndromes: the puzzle is almost solved". Pediatr Nephrol 1998; 12(4): 315-27.

2. Naesens $M$, Steels $P$, Verberckmoes R, Vanrenterghem Y, Kuypers D. "Bartter's and Gitelman's syndromes: from gene to clinic". Nephron Physiol 2004; 96(3): 65-78.

3. Zaffanello M, Taranta A, Palma A, Bettinelli A. "Type IV Bartter syndrome: report of two new cases". Pediatr Nephrol 2006; 21(6): 766-70.

4. Vaisbich MH, Fujimura MD, Koch VH. Bartter syndrome: benefits and side effects of long-term treatment. Pediatr Nephrol 2004; 19(8): 858-63. 